\title{
Change trend of monthly precipitation in China with an improved surface modeling method
}

\author{
Chen-Liang Wang $\cdot$ Na Zhao $\cdot$ Tian-Xiang Yue • \\ Ming-Wei Zhao $\cdot$ Cui Chen
}

Received: 28 September 2014/ Accepted: 30 December 2014/Published online: 14 January 2015

(C) Springer-Verlag Berlin Heidelberg 2015

\begin{abstract}
In this paper, a combination of a novel interpolation method and a local regression method was employed to improve the estimation accuracy of monthly precipitation over China. After the normalized processing and Box-Cox transformation of the data, we used the geographically weighted regression (GWR) method to describe the spatial precipitation trend, and then interpolated the residual by using a modified high accuracy surface modeling method (HASM-PRE). A high quality database of monthly precipitation with a resolution of $1 \mathrm{~km}^{2}$ was constructed based on the meteorological stations. Results showed that wet years and dry years appear alternatively, and trend analysis of precipitation data series from 1981 to 2010 showed that the probability of years with extreme precipitation has increased in recent years. Precipitation in winter is rather uncertain and more dynamic from year to year compared to precipitation in summer.
\end{abstract}

C.-L. Wang · N. Zhao (囚) - T.-X. Yue · M.-W. Zhao

State Key Laboratory of Resources and Environment Information System, Institute of Geographical Science and Natural Resources Research, Chinese Academy of Sciences, Beijing 100101, China

e-mail: zhaon@1reis.ac.cn

C.-L. Wang · M.-W. Zhao

University of Chinese Academy of Sciences,

Beijing 100049, China

C. Chen

Department of Environmental Informatics, Helmholtz

Centre for Environmental Research-UFZ, Permoserstraße 15, 04318 Leipzig, Germany
Keywords Box-Cox transformation - Geographically weighted regression - HASM - Precipitation - Time series . China

\section{Introduction}

Precipitation is a vital part of the hydrologic cycle and any changes in its patterns directly influence the water resources of any given region. Changes in precipitation quantity and frequency would also alter spatial and temporal distribution of runoff, soil moisture, vegetation growth, blue and green water resources, and groundwater reserves (Dore 2005; Robertson et al. 2007; An et al. 2014; Chen et al. 2014). Trend analysis of precipitation in different spatial scales would lead to a better understanding of the problems associated with floods, droughts and the availability of water for various uses with respect to future climate scenarios. The ability to accurately estimate precipitation is critical for hydrologic and ecological modeling and would certainly be of interest to water and energy planners. Traditionally, precipitation measurements have been available at rain gauges, but they are usually too sparsely distributed to capture the spatial variability, and poor interpolators can cause misleading results and conclusions. Development of accurate spatial precipitation data sets is important for the accurate modeling of soil moisture, agricultural crops growth, surface water and groundwater processes (Xu and Singh 1998; Vieux 2001; Hasenauer et al. 2003; Sato et al. 2004; Tong and Naramngam 2007; Rowhani et al. 2011; Antonellini et al. 2014; Samper et al. 2014). Many interpolation techniques were used to simulate precipitation (Frei and Schär 1998; Shen et al. 2001; Perry and Hollis 2005; Hofstra et al. 2008; Yatagay et al. 2012). However, there is no optimum method to define the spatial model of 
mean precipitation corresponding to an area of complex climatology (Hevesi et al. 1992; Attorre et al. 2007). The best interpolation method should be obtained by analyzing both the data and the spatial structure (Burrough and McDonnell 1998; Brus and Heuvelink 2007; Aalto et al. 2012).

High accuracy surface modeling (HASM) method has been widely used in digital elevation model (DEM) construction, ecosystem change, soil property interpolation (Yue et al. 2010a, b, 2011; Yue 2011; Shi et al. 2012). More recently, HASM has been used to investigate climate change in China and shows better simulation capability than other classical methods, such as Kriging, IDW and Spline (Yue et al. 2013; Zhao and Yue 2014). However, previous studies either ignored the normalization of precipitation, which can avoid the extreme values in the final results, or did not take into account the explanatory variables of it. Since the distribution of precipitation is controlled by several geographical and topographical factors, such as longitude, latitude and DEM, and it usually varies severely within a short distance, it is difficult to interpolate accurately using HASM when we ignore such obvious factors. Therefore, before we apply the HASM method, we should first use geographically weighted regression (GWR) method to give the spatial trend of precipitation for each month, which enables spatial non-stationarity in the statistical relationship (Brunsdon et al. 1996, 2001; Harris et al. 2010; Di Piazza et al. 2011; Bostan et al. 2012; Yue et al. 2013; Camera et al. 2014).

This study focuses on detecting and analyzing monthly precipitation trends within the recording period from 1981 to 2010 using GWR and HASM. Study areas and data are described in Sect. 2. Section 3 presents the methodology. The results are given in Sect. 4 where the conclusions are summarized.

\section{Study area and data}

China, covering an area of about $960,0000 \mathrm{~km}^{2}$, is the third largest country on earth, and China's topography varies enormously from high mountainous regions to inhospitable desert zones and flat, fertile plains. It is a predominantly mountainous country with a very distinct structural pattern. The extremely varied landforms of China affect the climate conditions in various ways. For precipitation, mountains effectively control the flow and passage of air masses, which may be blocked, diverted or channeled. In addition to the huge territory, extreme air distances and latitudinal and longitudinal distances also represent important controlling factors where it comes to climate. Because of its vast area and complex terrain, there are significant differences in precipitation. China is under the influence of the winter monsoon from October to March, during the dry season. The summer monsoon prevails from June to August when precipitation is plentiful. April, May and September are transitional months between the dry and wet seasons, resulting in remarkably variable precipitation for the whole region (Wang and $\mathrm{Li}$ 2007).

We used a set of monthly precipitation series from 752 stations for the period 1981-2010 (Fig. 1). The main geomorphologic characteristics of China and weather types affecting the country are such that the stations are representative and cover almost all climatic regions except the mountainous areas with a polar climate. The time series covers periods ranging 30 years.

\section{Methods}

Many studies show that the mixed spatial interpolation method, which combines regression method and interpolators, usually produces better results than other models in climate variables simulation (Burrough and McDonnell 1998; Ninyerola et al. 2000; Liu et al. 2004; He et al. 2005; Portales et al. 2010; Yue et al. 2013). Regression with residual correction can modify any local overestimation or underestimation. In this study, we employed the local regression method (GWR) to give the spatial distribution trend of precipitation and then interpolated the residual by HASM. This method can be summarized as,

$\operatorname{Pr} e_{\text {sim }}=\operatorname{Pr} e_{\text {trend }}+\operatorname{Pr} e_{\text {res }}$

where, $\operatorname{Pr} e_{s i m}$ is the final result, $\operatorname{Pr} e_{\text {trend }}$ is the trend value of precipitation and will be obtained by the GWR method. $\operatorname{Pr} e_{r e s}$ is the residual and will be interpolated by HASM.

Local regression method

Monthly precipitation is complex and the lower bound of zero means that most precipitation time series are not normally distributed (Legates 1991). Furthermore, in regions of high precipitation gradients there will also be high gradients in precipitation variances. Due to the large gradients in precipitation means and variances, the best method of calculating precipitation is to transform the original data first.

We first normalize the precipitation data to limit the extreme value,

$\overline{\overline{\operatorname{Pr} e_{i}}}=\frac{\operatorname{Pr} e_{i}}{\max \left\{\operatorname{Pr} e_{i, i=1, \ldots, n}\right\}}$

where, $\operatorname{Pr} e_{i}$ is the observed value, $\overline{\overline{\operatorname{Pr} e_{i}}}$ is the transformed data, $n$ is the number of observations.

Then we carry Box-Cox transform of $\overline{\overline{\operatorname{Pr} e_{i}}}$, which can give a more normal distribution and/or improved 
Fig. 1 Spatial distribution of the meteorological network in China

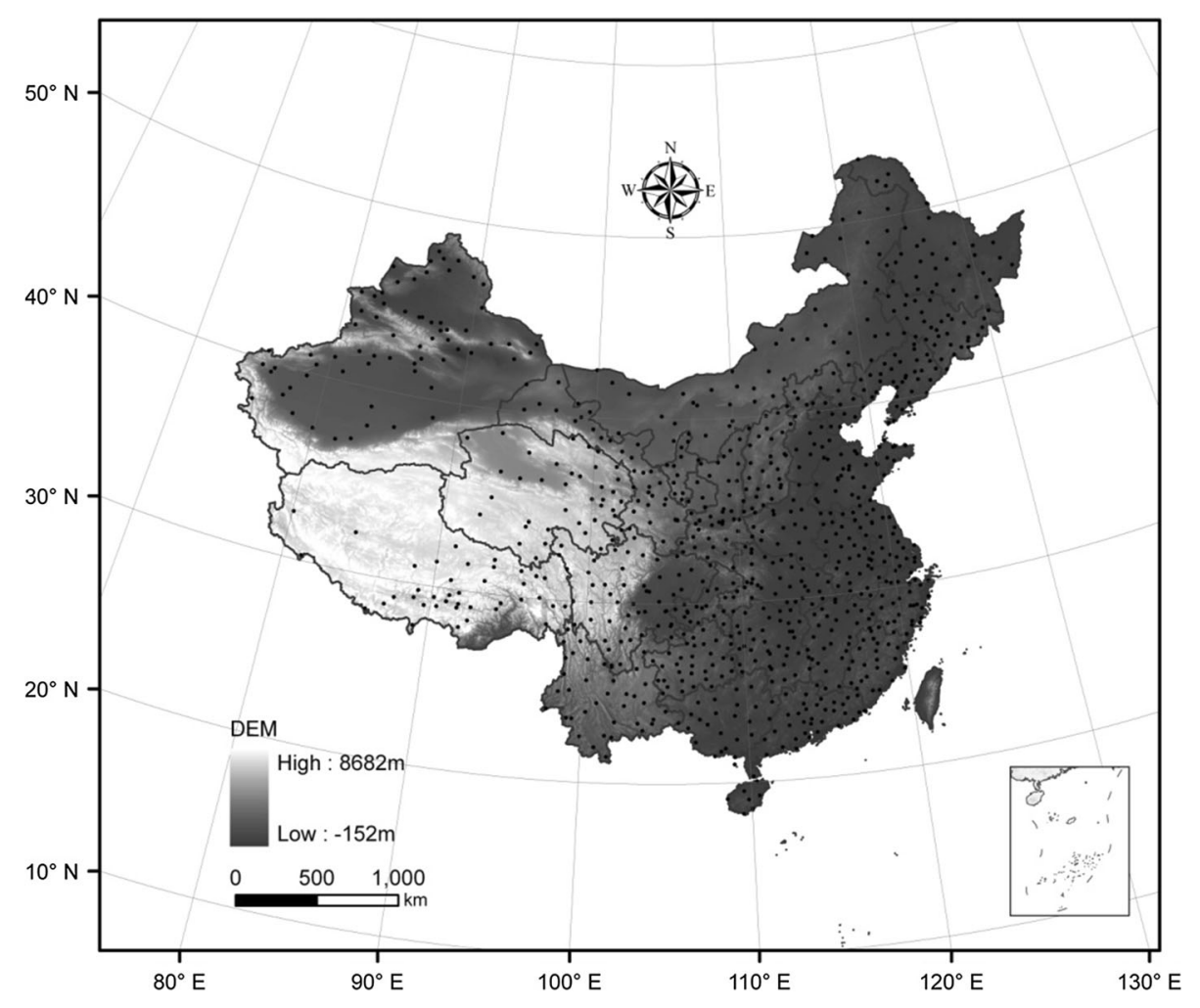

predictions (Box and Cox 1964; Sakia 1992). The formulation of this transformation is,

$\overline{\operatorname{Pr} e_{i}}= \begin{cases}\ln \overline{\overline{\operatorname{Pr} e_{i}}}, & \delta=0 \\ \frac{\overline{\operatorname{Pr} e_{i}} \delta}{\delta}, & \delta \neq 0\end{cases}$

where, $\overline{\operatorname{Pr} e_{i}}$ is the Box-Cox transformed data and $\delta$ is a suitable parameter, which is selected to make $\overline{\operatorname{Pr} e_{i}}$ obey normal distribution and thus satisfy the assumption of GWR method (Fotheringham et al. 2002). Studies have shown that this process avoids negative values in the results and is necessary for precipitation interpolation (Yue et al. 2013).

Unlike the ordinary linear regression model, GWR (Brunsdon et al. 1996; Loader 2004) enables the spatial drift of regression parameters to be identified, estimated and mapped, which is especially important for characterizing highly variable precipitation within China. The GWR method has been successfully used in precipitation research (Brunsdon et al. 2001; Wang et al. 2012) and the formulation of GWR can be written as,

$\operatorname{Pr} e_{\text {trend }}=d_{0,0}\left(x_{i}, y_{j}\right)+\sum_{i, j=1}^{N} a_{i, j} d_{i, j}\left(x_{i}, y_{j}\right)$

$\operatorname{Pr} e_{\text {trend }}$ is the trend value of $(i, j)$ grid-box; $d_{0,0}\left(x_{i}, y_{j}\right)$ is the intercept; $a_{i, j}$ is the explanatory variable and $d_{i, j}\left(x_{i}, y_{j}\right)$ is the corresponding coefficient which is a function of the position. $x_{i}, y_{i}$ are the longitude and latitude, respectively.
For different months, we select the independent variables from latitude $(\mathrm{y})$, longitude (x), elevation (DEM), slope, aspect, impact coefficient of aspect (Asp, Eq. (5)) and sky view factor (Svf, Eq. (6)) (Yue 2011) according to the value of the adjust $R^{2}$ in GWR.

$$
\begin{aligned}
& \text { Asp }=\left\{\begin{array}{cc}
-\cos \left(\pi \cdot\left(\frac{\text { Aspect }}{180^{\circ}}\right)\right) & \text { slope area } \\
0 & \text { flat area }
\end{array}\right. \\
& S v f=\frac{1+\cos \left(\pi \cdot\left(\text { Slope } / 180^{\circ}\right)\right)}{2}
\end{aligned}
$$

\section{HASM}

As an innovative method (Yue 2011), HASM is based on the fundamental theorem of surfaces, which ensures that a surface is uniquely defined by its first and second fundamental coefficients (Henderson 1998).

The equation of HASM-PRE is the following symmetric positive definite linear system (Zhao and Yue 2014),

$W x^{n+1}=v^{n}$

where $W=A^{T} A+B^{T} B+C^{T} C+\lambda^{2} S^{T} S, \quad v=A^{T} d+B^{T} q$ $+C^{T} p+\lambda^{2} S^{T} k, \lambda$ is a suitable parameter, see appendix for more details about HASM-PRE. The preconditioned conjugate gradient method can be used to solve Eq. (7) and the solution $x$ is the simulated value of the residual $\operatorname{Pr} e_{r e s}$ in Eq. (1). 


\section{Trend analysis of monthly precipitation data}

We calculated average precipitation from the land-based grid-box data set of this method and used the statistic analysis function of ArcGis 9.3. Monthly precipitation time series from 1981 to 2010 are displayed in Fig. 2.

Figure 2 indicates that, when the entire available data series for the period 1981-2010 is considered for trend detection at a monthly scale, of 30 values about 15 values are greater than the mean value. The precipitation of the 30 years appears to be a non-periodic oscillation phenomenon, wet years and dry years emerged almost alternatively and generally speaking there is no regular pattern for each month. Another important feature is that, of the
30 years considered, the years with the largest and lowest annual total precipitation were 2010 and 1986, respectively. The wetter years are 1983, 1990, 1998, 2005, 2008, and 2010, indicating that the probability of years with large precipitation has increased in recent years.

Table 1 gives the monthly mean precipitation and the standard deviation for the period 1981-2010. It is obvious that, for the 30 years considered, precipitation in August varied greatly from year to year, with a standard deviation of $11.3 \mathrm{~mm}$.

Standard deviation is closely related to the amount of precipitation in each month. However, the coefficient of variability (CV) (Eq. (8)) for a single variable aims to describe the dispersion of the variable in a way that does
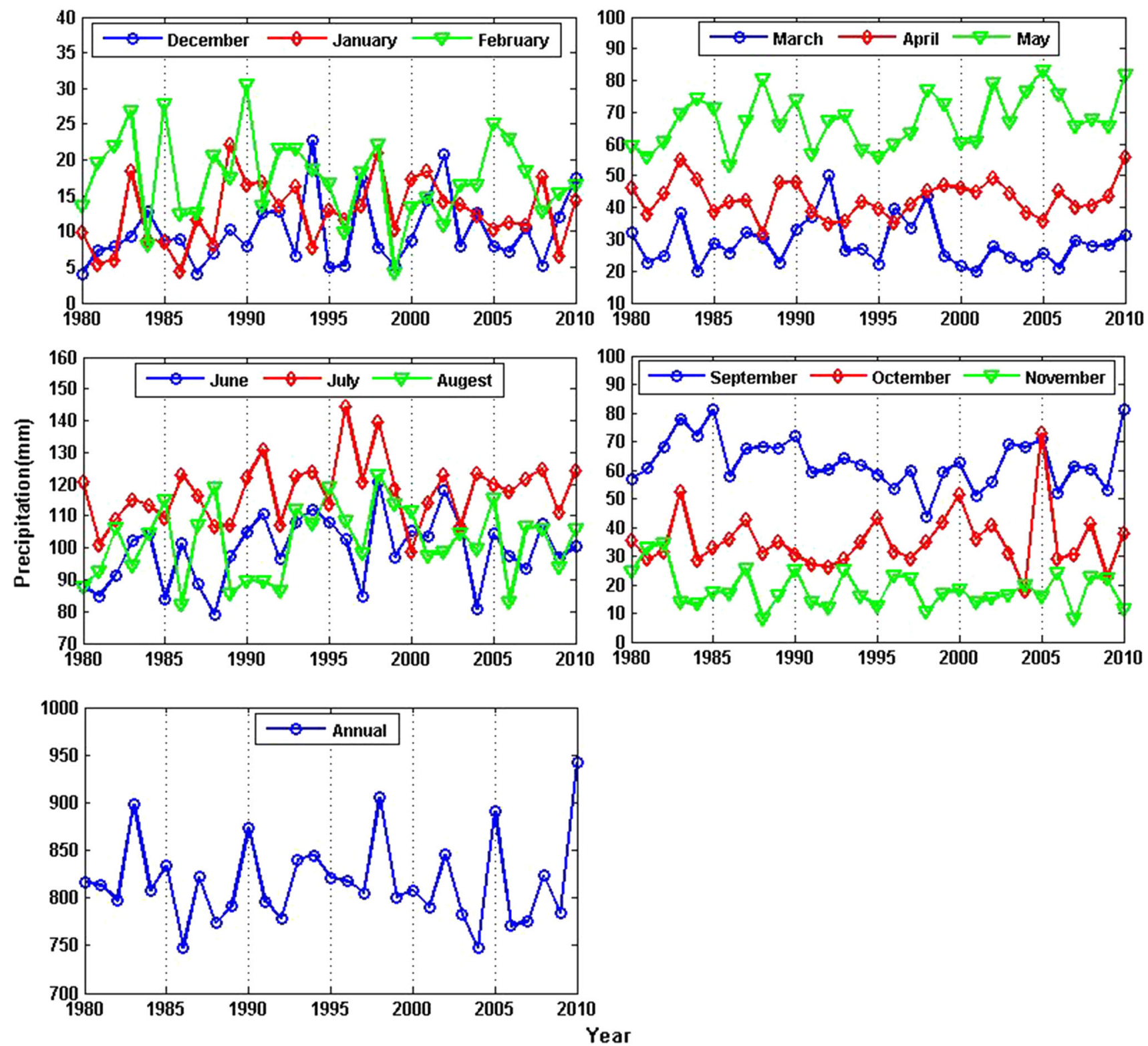

Fig. 2 Monthly precipitation time series for the period 1981-2010 
Table 1 Monthly mean precipitation and standard deviation for the period 1981-2010

\begin{tabular}{|c|c|c|c|c|c|c|c|c|c|c|c|c|}
\hline Month & Jan & Feb & Mar & Apr & May & Jun & Jul & Aug & Sep & Oct & Nov & Dec \\
\hline Mean (mm) & 12.7 & 17.6 & 28.7 & 42.7 & 67.8 & 99.7 & 117.6 & 102.6 & 63.2 & 35.2 & 18.1 & 10.1 \\
\hline Std (mm) & 4.7 & 6.0 & 7.3 & 5.7 & 8.4 & 10.5 & 10.2 & 11.3 & 8.8 & 10.4 & 6.6 & 4.7 \\
\hline
\end{tabular}

not depend on the variable's measurement unit. The higher the $\mathrm{CV}$, the greater the dispersion in the variable.

$C V=\frac{\frac{1}{N} \sum_{i=1}^{N}\left|x_{i}-\bar{x}\right|}{\bar{x}}$,

where, $x_{i}, i=1, \cdots, N$ is the studied variables, $\bar{x}$ is the mean value. Taking $\mathrm{CV}$ as a measure for inter-annual precipitation variability, a close relationship to monthly precipitation can be proved so that the coefficients increase with decreasing totals of precipitation, and vice versa (Fig. 3). Thus, small precipitation totals are the most variable, while large totals are the least variable. Rather small winter precipitation is also extremely uncertain and variable from year to year while by contrast heavy summer rains are less variable and more stable. The inter-annual variability of precipitation is greater for dry months, but smaller for wet months.

Table 2 gives the influence factors of precipitation in each month. We can see that the variable that has the highest influence on precipitation changes with months. For the winter months, the main affecting factors are $\mathrm{x}$, $y$ and DEM. However, for the summer months, the factors are different. The topographical factors have important influence on precipitation especially in the rainy season.

Finally, we will display the patterns of monthly mean precipitation distribution for the period 1981-2010 (Fig. 4), and use the same legend to show the precipitation change pattern. Here, we just show a single month per season: January (winter), April (spring), July (summer) and October (autumn). It is clear that from spring to summer,

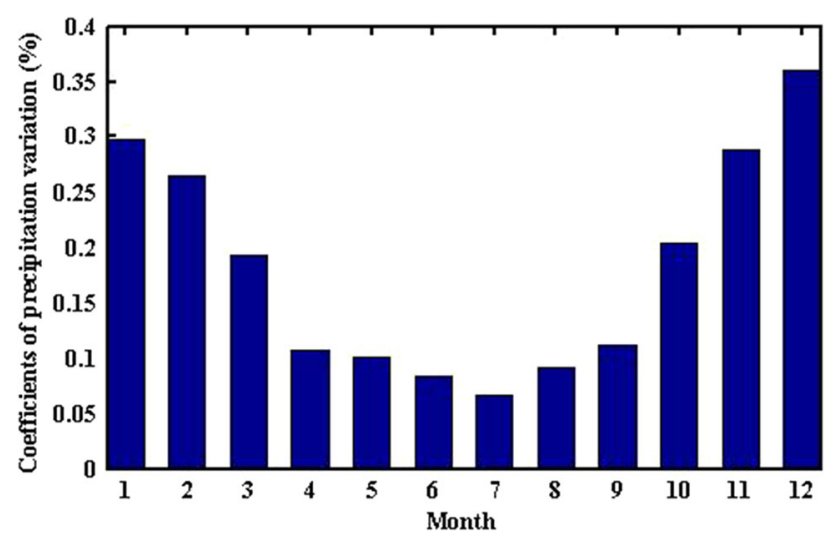

Fig. 3 Monthly coefficients of precipitation variation
Table 2 Influence factors of precipitation in each month

\begin{tabular}{llll}
\hline Month & Influence factors & Month & Influence factors \\
\hline Jan & x, y, DEM & Jul & x, y, DEM, slope, Svf \\
Feb & x, y, DEM, slope & Aug & x, y, DEM, slope, Asp \\
Mar & x, y, DEM, slope & Sep & x, y, DEM, slope \\
Apr & x, y, DEM, slope, aspect & Oct & x, y, DEM, slope \\
May & x, y, DEM, slope, aspect & Nov & x, y, DEM, slope \\
Jun & x, y, DEM, slope, aspect & Dec & x, y, DEM, slope \\
\hline
\end{tabular}

the comparably wet parts expanded from southeast to northwest, clearly indicating an increasing precipitation pattern from April to July. Although the amount and distribution of precipitation for autumn (October) also varied widely over space, the wetter parts of China were narrowed down, and the amount and distribution of precipitation narrowed to its minimal size in winter. There exist distinct differences of precipitation between different seasons and areas because of the distance from the sea, great interior extent, complicated terrain and elevation. China is under the influence of the winter monsoon from October to March, during which period there is the dry season. The summer monsoon prevails from June to August when precipitation is plentiful. April is the transitional month between the dry and wet seasons. Variability of precipitation is remarkable and the seasonal precipitation distribution is uneven throughout China. The figures indicate a steep precipitation gradient from northwest to southeastern parts of the country and show how precipitation changes from month to month.

HASM-PRE, which was first proposed to simulate the annual mean precipitation, showed higher accuracy than the previous version of HASM (Zhao and Yue 2014). In this research, we combine HASM-PRE and GWR to improve the accuracy of monthly interpolation results. Next, we will investigate the performance of HASM-PRE and the mixed interpolation method given in this study. A total of 100 stations were selected at random from the data set and withheld from the interpolation calculations. We calculate RMSEs and MAEs to compare the accuracy of HASM-PRE and the mixed interpolation method. The results are shown in Table 3. Note that HASM-PRE is based on the fundamental theorem of surface theory, and it does not consider the geological factors. We found that, when combining with GWR method, the accuracy of the mixed interpolation method is much higher than HASM- 


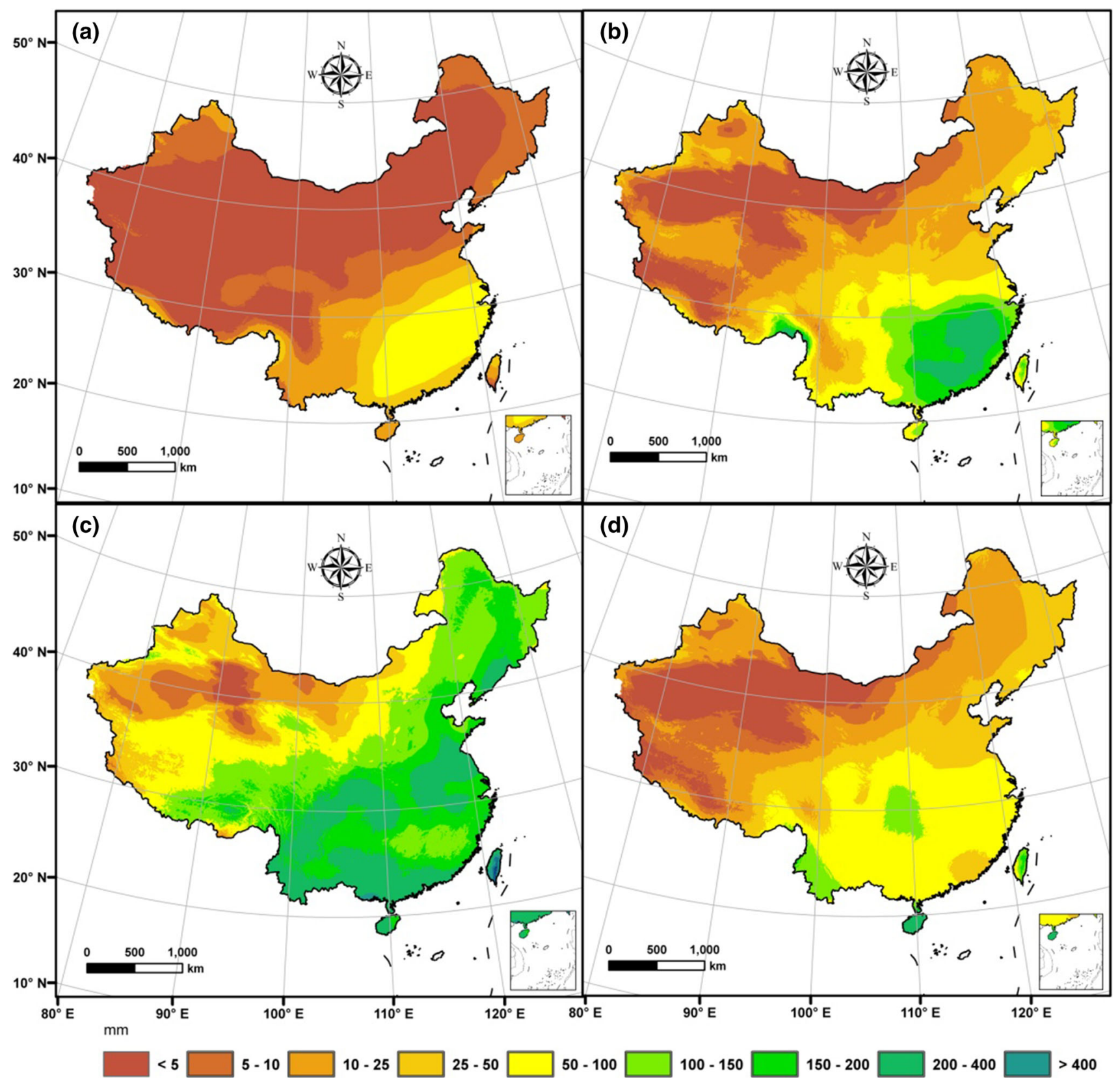

Fig. 4 Monthly mean precipitation over the period 1981-2010: (a) January; (b) April; (c) July; (d) October

PRE. The reason for this is the introduction of the geographical and topographical factors in the GWR method. For the extreme values, we compared the differences between the observed values and the simulated values obtained by HASM-PRE and the mixed interpolation method. Table 4 shows that, the mixed interpolation method has the ability to obtain better results compared to HASM-PRE when simulate extremes.
Table 3 Errors for monthly mean precipitation generated by HASMPRE and the mixed interpolation method

\begin{tabular}{llllll}
\hline Errors & Methods & Jan & Apr & Jul & Oct \\
\hline RMSE (mm) & HASM-PRE & 3.71 & 9.54 & 30.25 & 9.16 \\
& Mixed & 2.70 & 4.10 & 17.41 & 6.04 \\
\multirow{2}{*}{ MAE (mm) } & HASM-PRE & 2.20 & 5.37 & 19.13 & 5.75 \\
& Mixed & 1.54 & 2.32 & 10.76 & 3.85 \\
\hline
\end{tabular}


Table 4 Simulation results of the extreme values

\begin{tabular}{llllrrrrr}
\hline Methods & Jan & \multicolumn{3}{c}{ Apr } & \multicolumn{1}{c}{ Jul } & \multicolumn{3}{c}{ Oct } \\
\hline Observed (mm) & 0.13 & 83.93 & 1.32 & 262.81 & 7.57 & 482.76 & 0.87 & 129.32 \\
HASM-PRE (mm) & 0.83 & 79.74 & 1.49 & 220.99 & 12.89 & 405.50 & 1.77 & 107.75 \\
Mixed (mm) & 0.30 & 82.42 & 1.44 & 255.29 & 8.08 & 457.32 & 1.21 & 118.31 \\
\hline
\end{tabular}

Fig. 5 Relative errors produced by the mixed interpolation method

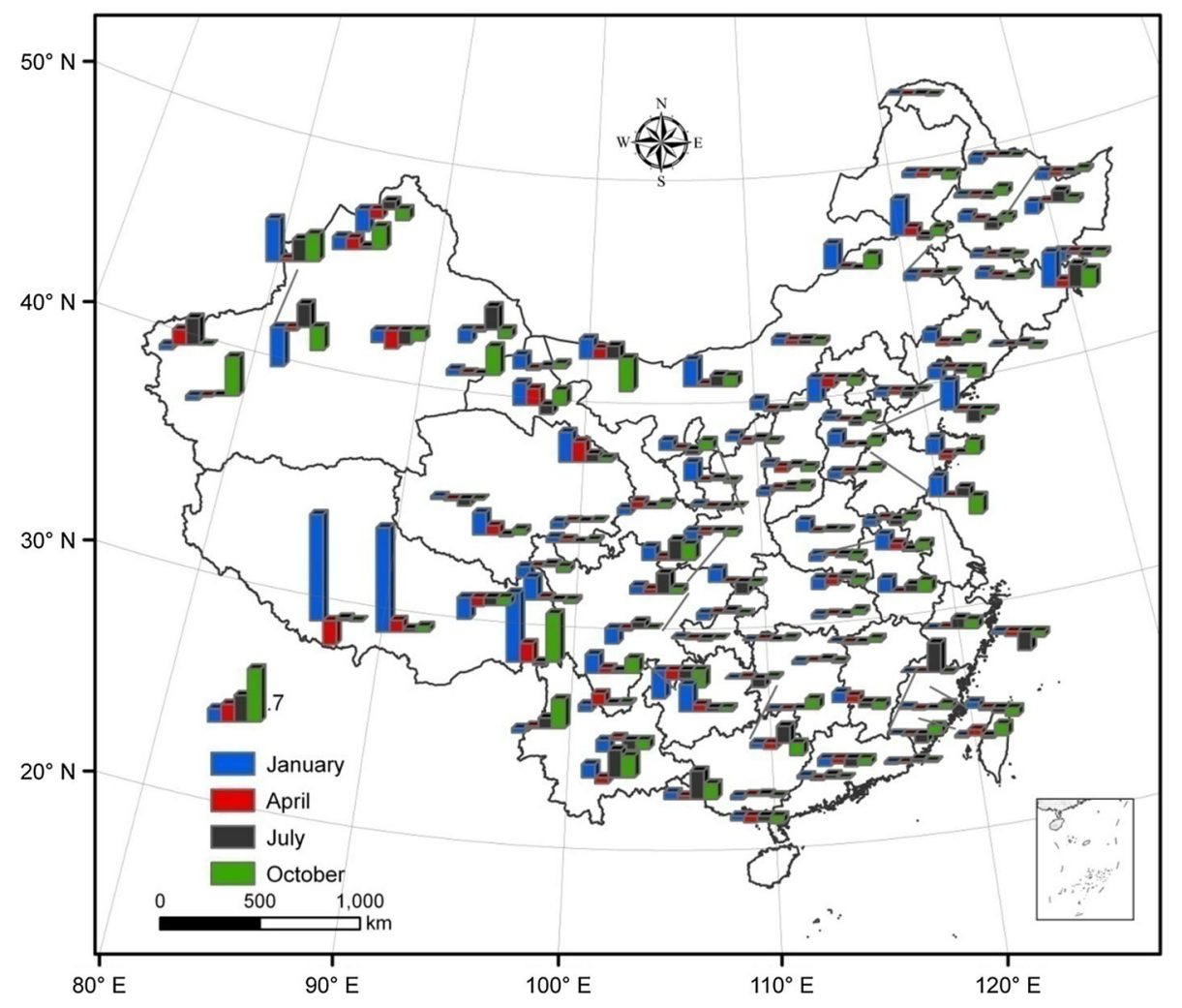

Figure 5 displays the relative errors in different months at the verification points produced by the mixed interpolation method. It is evident that large errors usually occur in western China, the border of China and rough mountain areas. For different months, the distribution of the errors is different. In January, the regions with large errors are rough mountain areas and the southwest of China. In July, large errors can be observed in southeastern coastal areas and the northwest boundary of China. The largest error in January is higher than that in July. For the considered months, the errors in April are the smallest on the whole.

\section{Conclusions}

This paper applies a combination of a local regression method and a high accuracy surface modeling method (HASM-PRE) to build up a new high quality precipitation series from 1981-2010. Studies show that the dataset has feasibly described the features of Chinese climate change. For the monthly precipitation dataset concerning
1981-2010, we found that wet years and dry years emerged almost alternately. Of the 30 years taken into consideration, about 15 years had a large precipitation amount which was greater than the mean precipitation of the 30 years. The precipitation of the 30 years appears to be a non-periodic oscillation phenomenon and more generally there is no regular pattern for each month. Of the 30 years concerned, the years with the largest and lowest annual total precipitation are 2010 and 1986, respectively. The wetter years were 1983, 1990, 1998, 2005, 2008, and 2010, indicating that the probability of years with large precipitation has increased in recently years. In addition, the coefficient of variability reveals that precipitation in winter is rather uncertain and variable from year to year while rains in summer are more stable.

We can conclude that the method used in this study prefer to focus on regression rather than HASM. That is to say the result is determined primarily by the regression method. Because China is such a vast area, precipitation is affected by many geographical and topographical factors, which means that more accurate results can be obtained by 
using local regression methods with more explanatory variables, especially for short time scales. Except the variables considered in this study, further researches should be concentrate on different explanatory variables for different months to gain more accurate results.

Acknowledgments This work is supported by the Program of National Natural Science of China (91325204) and by National High- information such as shape. The Christoffel symbols $\Gamma_{11}^{1}, \Gamma_{11}^{2}, \Gamma_{22}^{1}, \Gamma_{22}^{2}$ depend only on the first fundamental coefficients and their derivatives (Somasundaram 2005).

Let $\left\{\left(x_{i}, y_{j}\right) \mid 0 \leq i \leq I+1,0 \leq j \leq J+1\right\}$ be the computational grids and $h$ be the grid size in $x$ and $y$ directions. By using finite difference methods, Eq. (9) can be changed to,

$$
\left\{\begin{array}{l}
\frac{f_{i+1, j}^{n+1}-2 f_{i, j}^{n+1}+f_{i-1, j}^{n+1}}{h^{2}}=\left(\Gamma_{11}^{1}\right)_{i, j}^{n} \frac{f_{i+1, j}^{n}-f_{i-1, j}^{n}}{2 h}+\left(\Gamma_{11}^{2}\right)_{i, j}^{n} \frac{f_{i, j+1}^{n}-f_{i, j-1}^{n}}{2 h}+\frac{L_{i, j}^{n}}{\sqrt{E_{i, j}^{n}+G_{i, j}^{n}-1}} \\
\frac{f_{i, j+1}^{n+1}-2 f_{i, j}^{n+1}+f_{i, j-1}^{n+1}}{h^{2}}=\left(\Gamma_{22}^{1}\right)_{i, j}^{n} \frac{f_{i+1, j}^{n}-f_{i-1, j}^{n}}{2 h}+\left(\Gamma_{22}^{2}\right)_{i, j}^{n} \frac{f_{i, j+1}^{n}-f_{i, j-1}^{n}}{2 h}+\frac{N_{i, j}^{n}}{\sqrt{E_{i, j}^{n}+G_{i, j}^{n}-1}} \\
\frac{f_{i+1, j}^{n+1}-f_{i+1, j-1}^{n+1}-f_{i-1, j+1}^{n+1}-2 f_{i, j}^{n+1}+f_{i, j-1}^{n+1}+f_{i, j+1}^{n+1}+f_{i-1, j}^{n+1}}{2 h^{2}}=\left(\Gamma_{12}^{1}\right)_{i, j}^{n} \frac{f_{i+1, j}^{n}-f_{i-1, j}^{n}}{2 h}+\left(\Gamma_{12}^{2}\right)_{i, j}^{n} \frac{f_{i, j+1}^{n}-f_{i, j-1}^{n}}{2 h}+\frac{M_{i, j}^{n}}{\sqrt{E_{i, j}^{n}+G_{i, j}^{n}-1}}
\end{array}\right.
$$

tech R\&D Program of the Ministry of Science and Technology of the People's Republic of China (2013AA122003).

\section{Appendix}

The equations of HASM-PRE can be formulated as (Zhao and Yue 2014),

$$
\left\{\begin{array}{l}
f_{x x}=\Gamma_{11}^{1} f_{x}+\Gamma_{11}^{2} f_{y}+\frac{L}{\sqrt{E+G-1}} \\
f_{y y}=\Gamma_{22}^{1} f_{x}+\Gamma_{22}^{2} f_{y}+\frac{N}{\sqrt{E+G-1}} \\
f_{x y}=\Gamma_{12}^{1} f_{x}+\Gamma_{12}^{2} f_{y}+\frac{M}{\sqrt{E+G-1}}
\end{array}\right.
$$

where, $E=1+f_{x}^{2} F=f_{x} \cdot f_{y} G=1+f_{y}^{2}, L=\frac{f_{x x}}{\sqrt{1+f_{x}^{2}+f_{y}^{2}}}$,

$$
M=\frac{f_{x y}}{\sqrt{1+f_{x}^{2}+f_{y}^{2}}}
$$

$$
N=\frac{f_{y y}}{\sqrt{1+f_{x}^{2}+f_{y}^{2}}},
$$

$\Gamma_{11}^{1}=\frac{1}{2}\left(G E_{x}-2 F F_{x}+F E_{y}\right)\left(E G-F^{2}\right)^{-1}$,

$\Gamma_{11}^{2}=\frac{1}{2}\left(E F_{x}-2 E E_{y}+F E_{x}\right)\left(E G-F^{2}\right)^{-1}$,

$\Gamma_{22}^{1}=\frac{1}{2}\left(2 G F_{y}-2 G G_{x}+F G_{y}\right)\left(E G-F^{2}\right)^{-1}$,

$\Gamma_{22}^{2}=\frac{1}{2}\left(E G_{y}-2 F F_{y}+F G_{x}\right)\left(E G-F^{2}\right)^{-1}$,

$\Gamma_{12}^{1}=\frac{1}{2}\left(G E_{y}-F G_{x}\right)\left(E G-F^{2}\right)^{-1}$,

$\Gamma_{12}^{2}=\frac{1}{2}\left(E G_{x}-F E_{y}\right)\left(E G-F^{2}\right)^{-1} . E, F, G$ are the first fundamental coefficients of the surface and represent the local details of it while $L, M, N$ are the second fundamental coefficients of the surface and denote macroscopical where, $n$ represents the number of iterations, $E_{i, j}^{n}=1+\left(\frac{f_{i+1, j}^{n}-f_{i-1, j}^{n}}{2 h}\right)^{2}, F_{i, j}=\left(\frac{f_{i+1, j}^{n}-f_{i-1, j}^{n}}{2 h}\right)\left(\frac{f_{i, j+1}^{n}-f_{i, j-1}^{n}}{2 h}\right)$,

$G_{i, j}^{n}=1+\left(\frac{f_{i, j+1}^{n}-f_{i, j-1}^{n}}{2 h}\right)^{2}, \quad L_{i, j}^{n}=\frac{\frac{f_{i-1, j}^{n}-2 i_{i, j}^{n}+f_{i+1, j}^{n}}{h^{2}}}{\sqrt{1+\left(\frac{f_{i+1, j}^{n}-f_{i-1, j}^{n}}{2 h}\right)^{2}+\left(\frac{f_{i, j+1}^{n}-f_{i, j-1}^{n}}{2 h}\right)^{2}}}$

$M_{i, j}^{n}=\frac{\frac{f_{i+1, j}^{n}-f_{i+1, j-1}^{n}-f_{i-1, j+1}^{n}-2 f_{i, j}^{n}+f_{i, j-1}^{n}+f_{i, j+1}^{n}+f_{i-1, j}^{n}}{2 h^{2}}}{\sqrt{1+\left(\frac{f_{i+1, j}^{n}-f_{i-1, j}^{n}}{2 h}\right)^{2}+\left(\frac{f_{i, j+1}^{n}-f_{i, j-1}^{n}}{2 h}\right)^{2}}}$

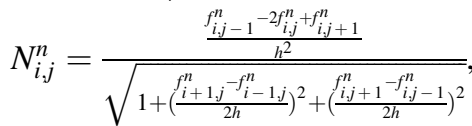

$\left(\Gamma_{11}^{1}\right)_{i, j}^{n}=\frac{G_{i, j}^{n}\left(E_{i+1, j}^{n}-E_{i-1, j}^{n}\right)-2 F_{i, j}^{n}\left(F_{i+1, j}^{n}-F_{i-1, j}^{n}\right)+F_{i, j}^{n}\left(E_{i, j+1}^{n}-E_{i, j-1}^{n}\right)}{4\left(E_{i, j}^{n} G_{i, j}^{n}-\left(F_{i, j}^{n}\right)^{2}\right) h}$,

$\left(\Gamma_{11}^{2}\right)_{i, j}^{n}=\frac{2 E_{i, j}^{n}\left(F_{i+1, j}^{n}-F_{i-1, j}^{n}\right)-E_{i, j}^{n}\left(E_{i, j+1}^{n}-E_{i, j}^{n}\right)-F_{i, j}^{n}\left(E_{i, j+1}^{n}-E_{i, j-1}^{n}\right)}{4\left(E_{i, j}^{n} G_{i, j}^{n}-\left(F_{i, j}^{n}\right)^{2}\right) h}$,

$\left(\Gamma_{22}^{1}\right)_{i, j}^{n}=\frac{2 G_{i, j}^{n}\left(F_{i, j+1}^{n}-F_{i, j-1}^{n}\right)-G_{i, j}^{n}\left(G_{i+1, j}^{n}-G_{i-1, j}^{n}\right)-F_{i, j}^{n}\left(G_{i, j+1}^{n}-G_{i, j-1}^{n}\right)}{4\left(E_{i, j}^{n} G_{i, j}^{n}-\left(F_{i, j}^{n}\right)^{2}\right) h}$,

$\left(\Gamma_{22}^{2}\right)_{i, j}^{n}=\frac{E_{i, j}^{n}\left(G_{i, j+1}^{n}-G_{i, j-1}^{n}\right)-2 F_{i, j}^{n}\left(F_{i, j+1}^{n}-F_{i, 1-1}^{n}\right)+F_{i, j}^{n}\left(G_{i+1, j}^{n}-G_{i-1, j}^{n}\right)}{4\left(E_{i, j}^{n} G_{i, j}^{n}-\left(F_{i, j}^{n}\right)^{2}\right) h}$.

$\left(\Gamma_{12}^{1}\right)_{i, j}^{n}=\frac{G_{i, j}^{n}\left(E_{i+1, j}^{n}-E_{i-1, j}^{n}\right)-F_{i, j}^{n}\left(G_{i+1, j}^{n}-G_{i-1, j}^{n}\right)}{4\left(E_{i, j}^{n} G_{i, j}^{n}-\left(F_{i, j}^{n}\right)^{2}\right) h}$,

$\left(\Gamma_{12}^{2}\right)_{i, j}^{n}=\frac{E_{i, j}^{n}\left(G_{i+1, j}^{n}-G_{i-1, j}^{n}\right)-F_{i, j}^{n}\left(E_{i, j+1}^{n}-E_{i, j-1}^{n}\right)}{4\left(E_{i, j}^{n} G_{i, j}^{n}-\left(F_{i, j}^{n}\right)^{2}\right) h}$.

The constraint equation about sample point information is added to Eq. (10) and the formulation of HASM-PRE can be expressed as,

$$
\left\{\begin{array}{c}
\min \left\|\left[\begin{array}{l}
A \\
B \\
C
\end{array}\right] z^{n+1}-\left[\begin{array}{l}
d \\
q \\
p
\end{array}\right]^{n}\right\|_{2} \\
\text { s.t. } S z^{(n+1)}=k
\end{array}\right.
$$

where, 
$A=\left[\begin{array}{ccccc}-2 I & I & & & \\ I & -2 I & I & & \\ & \ddots & \ddots & \ddots & \\ & & I & -2 I & I \\ & & & I & -2 I\end{array}\right]_{(I+2) \cdot(J+2) \times(I+2) \cdot(J+2)}$,

$I=\left[\begin{array}{lll}1 & & \\ & \ddots & \\ & & 1\end{array}\right]_{(J+2) \times(J+2)}$,

$B=\left[\begin{array}{lll}\widetilde{B} & & \\ & \ddots & \\ & & \widetilde{B}\end{array}\right]_{(I+2) \cdot(J+2) \times(I+2) \cdot(J+2)}$,

$\widetilde{B}=\left[\begin{array}{ccccccc}-2 & 1 & & & & & \\ 1 & -2 & 1 & & & & \\ & \ddots & \ddots & \ddots & & & \\ & & 1 & -2 & 1 & & \\ & & & \ddots & \ddots & \ddots & \\ & & & & 1 & -2 & 1 \\ & & & & & 1 & -2\end{array}\right]_{(J+2) \times(J+2)}$

$C=\left[\begin{array}{ccccc}C_{1} & -C_{1} & & & \\ C_{3} & C_{2} & C_{4} & & \\ & \ddots & \ddots & \ddots & \\ & & C_{3} & C_{2} & C_{4} \\ & & & C_{1} & -C_{1}\end{array}\right]_{(I+2) \cdot(J+2) \times(I+2) \cdot(J+2)}$,

$C_{1}=\left[\begin{array}{ccccc}1 & -1 & & & \\ 1 / 2 & 0 & -1 / 2 & & \\ & \ddots & \ddots & \ddots & \\ & & 1 / 2 & 0 & -1 / 2 \\ & & & 1 & -1\end{array}\right]_{(J+2) \times(J+2)}$

$C_{2}=\left[\begin{array}{ccccc}0 & 0 & 0 & & \\ 1 / 2 & -1 & 1 / 2 & & \\ & \ddots & \ddots & \ddots & \\ & & 1 / 2 & -1 & 1 / 2 \\ & & 0 & 0 & 0\end{array}\right]_{(J+2) \times(J+2)}$,

$C_{3}=\left[\begin{array}{ccccc}1 / 2 & -1 / 2 & & & \\ & 1 / 2 & -1 / 2 & & \\ & & \ddots & \ddots & \\ & & & 1 / 2 & -1 / 2 \\ & & & 1 / 2 & -1 / 2\end{array}\right]_{(J+2) \times(J+2)}$
$C_{4}=\left[\begin{array}{ccccc}-1 / 2 & 1 / 2 & & & \\ -1 / 2 & 1 / 2 & & & \\ & \ddots & \ddots & & \\ & & -1 / 2 & 1 / 2 & \\ & & & -1 / 2 & 1 / 2\end{array}\right]_{(J+2) \times(J+2)}$

and $S(l,(i-1) \cdot J+j)=1, k(l)=\bar{f}_{i, j}$, this means the sampled value is $\bar{f}_{i, j}$ at the $l$ the sampling point $\left(x_{i}, y_{j}\right)$.

By using the weighting method (Golub and Van Loan 2009), the problem is equivalent to the symmetric positive definite linear system,

$W x^{n+1}=v^{n}$

where $W=A^{T} A+B^{T} B+C^{T} C+\lambda^{2} S^{T} S, v=A^{T} d+B^{T} q$ $+C^{T} p+\lambda^{2} S^{T} k, \lambda$ is a suitable parameter. Since the matrix $W$ is ill-conditioned, the preconditioned conjugate gradient method (PCG) is used to solve Eq. (12).

The code of PCG is as follows:

Algorithm: Preconditioned Conjugate Gradients (Golub and Van Loan 2009):

$$
\begin{aligned}
& \text { Given an initial } x_{0} \text {, } \\
& k=0, \quad r_{0}=v-W x_{0} \\
& \text { while }\left(r_{k} \neq 0\right) \\
& \text { solve } M z_{k}=r_{k} \\
& k=k+1 \\
& \text { If } k=1 \\
& p_{1}=z_{0} \\
& \beta_{k}=r_{k-1}^{T} z_{k-1} / r_{k-2}^{T} z_{k-2} \\
& p_{k}=z_{k-1}+\beta_{k} p_{k-1}
\end{aligned}
$$

end

$x=x_{k}$ 
The major amount of calculation is from the linear system $M z_{k}=r_{k}$. The choice of a good preconditioner can have a dramatic effect upon the rate of convergence. We then employ the incomplete Cholesky preconditioner to speed up the above algorithm.

The incomplete Cholesky preconditioner (ICCG) has been very popular (Meijerink and van der Vorst 1977). Suppose the incomplete Cholesky factorization of $W$ is as follows: $W=M+R=L L^{T}+R$. Where $L$ is a lower triangular matrix with the property that $M=L L^{T}$ is close to $W$ and $L$ has the same sparsity structure with $W$. For the complete Cholesky factorization, $W=L L^{T}$. However, for the incomplete Cholesky factorization, $W-R=L L^{T}$. The structure of $L$ can be controlled by the matrix $R$. This avoid the complete Cholesky factorization which destroy the sparsity structure of $W$. Consider that there exist many zero elements of $R$ and the nonzero elements value of $R$ are small in actual computation. In this paper, we consider the non-filled Cholesky factorization of $W$, that is, the position of $L$ is zero if the corresponding position of $W$ is zero. The code of this algorithm is as follows:

$$
\begin{aligned}
& W(k, k)=\sqrt{W(k, k)} \\
& \text { for } i=k+1: n \\
& \text { if } W(i, k) \neq 0 \\
& W(i, k)=W(i, k) / W(k, k) \\
& \text { end } \\
& \text { end } \quad j=k+1: n \\
& \text { for } i=j: n \\
& \text { for } i=6(i, j) \neq 0 \\
& \text { if } W(i, j)-W(i, k) / W(j, k) \\
& \text { end } \\
& \text { end } \\
& \text { end }
\end{aligned}
$$

In the actual computation process, to take advantage of the large number of zeros in matrices $W$ and $L$, we adopt the block compressed sparse row (BCSR) format. $M z_{k}=r_{k}$ in the program can be transformed to $L^{T} z_{k}=y_{k}$ and $L y_{k}=$ $r_{k}$ and the computational cost of these is $O\left(n^{2}\right)$.

\section{References}

Aalto J, Pirinen P, Heikkinen J, Venalainen A (2012) Spatial interpolation of monthly climate data for Finland: comparing the performance of kriging and generalized additive models. Theor Appl Climatol 112(1-2):99-111

An YZ, Gao W, Gao ZQ (2014) Characterizing land condition variability in Northern China from 1982 to 2011. Environ Earth Sci 72(3):663-676

Antonellini M, Dentinho T, Khattabi E, Mollema PN, Silva V, Silverira P (2014) An integrated methodolody to assess future water resources under land use and climate change: an application to the Tahadart drainage basin (Morocco). Environ Earth Sci 71:1839-1853

Attorre F, Alfo M, Sanctis MD, Francesconi F, Bruno F (2007) Comparison of interpolation methods for mapping climatic and bioclimatic variables at regional scale. Int $\mathrm{J}$ Climatol 27:1825-1843

Bostan PA, Heuvelink GBM, Akyurek SZ (2012) Comparison of regression and kriging techniques for mapping the average annual precipitation of Turkey. Int J Appl Earth Obs Geoinf 19:115-126

Box GEP, Cox DR (1964) An analysis of transformation. J R Stat Soc Ser B 26:211-252

Brunsdon C, Fotheringham S, Charlton M (1996) Geographically weighted regression-modelling spatial non-stationarity. Geogr Anal 28:281-289

Brunsdon C, Mcclatchey J, Unwin DJ (2001) Spatial variations in the average rainfall-altitude relationship in Great Britain: An approach using geographically weighted regression. Int J Climatol 21:455-466

Brus D, Heuvelink G (2007) Optimization of sample patterns for universial kriging of environmental variables. Geoderma 138:86-95

Burrough PA, McDonnell RA (1998) Principles of geographical information systems. Oxford University Press, New York

Camera C, Bruggeman A, Hadjinicolaou P, Pashiardis S, Lange MA (2014) Evaluation of interpolation techniques for the creation of gridded daily precipitation $\left(1 \times 1 \mathrm{~km}^{2}\right)$; Cyprus, 1980-2010. J Geophys Res Atmos 119:693-712

Chen C, Hagemann S, Liu JG (2014) Assessment of impact of climate change on the blue and green water resources in large river basins in China. Environ Earth Sci. doi:10.1007/s12665-014-3782-8

Di Piazza A, Lo Conti F, Noto LV, Viola F, La Loggia G (2011) Comparative analysis of different techniques for spatial interpolation of rainfall data to create a serially complete monthly time series of precipitation for Sicily, Italy. Int J Appl Earth Obs Geoinf 13:396-408

Dore MHI (2005) Climate change and changes in global precipitation patterns: what do we know? Environ Int 31:1167-1181

Fotheringham AS, Brunsdon C, Charlton M (2002) Geographically weighted regression: the analysis of spatially varying relationships. Wiley, New York

Frei C, Schär C (1998) A precipitation climatology of the alps from high-resolution rain-gauge observations. Int $\mathrm{J}$ Climatol 18:873-900

Golub GH, Van Loan CF (2009) Matrix computations. Posts \& Telecom Press, Beijing

Harris P, Fotheringham AS, Juggins S (2010) Robust geographically weighted regression: a technique for quantifying spatial relationships between freshwater acidification critical loads and catchment attributes. Annals Assoc A 100:286-306

Hasenauer H, Merganicova K, Petritsch R, Pietsch SA, Thomton PE (2003) Validation daily climate interpolations over complex terrain in Austria. Agric For Meteorol 119:87-107

He HY, Guo ZH, Xiao WF (2005) Review on spatial interpolation techniques of rainfall. Chin J Ecol 24:1187-1191

Henderson DW (1998) Differential geometry. Prentice-Hall, London

Hevesi JA, Istok JD, Flint AL (1992) Precipitation estimation in mountainous terrain using multivariate geostatistics. I. Structural analysis. J Appl Meteoro 31:661-676 
Hofstra N, Haylock M, New M, Jones P, Frei C (2008) Comparison of six methods for the interpolation of daily European climate data. J Geophys Res 113:D21110

Legates DR (1991) An evaluation of procedures to estimate monthly precipitation probilities. J Hydrol 125:129-140

Liu XA, Yu GR, Fan LS, Li ZQ, He HL, Guo XB, Ren CY (2004) Study on spatialization technology of terrestrial eco-information in China(III): Temperature and precipitation. J Nat Res 19:818-825

Loader C (2004) Smoothing: local regression techniques. Springer, In Handbook of Computational Techniques

Meijerink JA, van der Vorst HA (1977) An iterative solution method for linear systems of which the coefficient matrix is a symmetric M-Matrix. Math Comput 31:148-162

Ninyerola M, Pons X, Roure JM (2000) A methodological approach of climatological modeling of air temperature and precipitation through GIS techniques. Int J Climatol 20:1823-1841

Perry M, Hollis D (2005) The generation of monthly gridded datasets for a range of climate variables over theUK. Int $\mathrm{J}$ Climatol 25:1041-1054

Portales C, Boronat N, Pardo-Pascual JE, Balaguer-Beser A (2010) Seasonal precipitation interpolation at the Valencia region with multivariate methods using geographic and topographic information. Int J Climatol 30:1547-1563

Robertson AW, Ines AVM, Hansen JW (2007) Downscaling of seasonal precipitation for crop simulation. J Appl Mete 46:677-693

Rowhani P, Lobell BD, Linderman M, Ramankutty N (2011) Climate variability and crop production in Tanzania. Agric For Meteorol 151:449-460

Sakia RM (1992) The Box-Cox transformation technique: a review. J R Stat Soc Ser D 41:169-178

Samper J, Li YM, Pisani B (2014) An evaluation of climate change impacts on groundwater flow in the Plana de La Galera and Tortosa alluvial aquifers (Spain). Environ Earth Sci. doi:10. 1007/s12665-014-3734-3

Sato YS, Yamashita F, Sugiura Y (2004) FIB-assisted TEM study of an oxide array in the root of a friction stirweided aluminum alloy. Scripta Mate 50:365-369

Shen SSP, Dzikowski P, Guilon L, Griffith D (2001) Interpolation of 1961-97 daily temperature and precipitation data onto Alberta polygons of ecodistrict and soil landscapes of Canada. J Appl Meteorol 40:2162-2177

Shi WJ, Liu JY, Du ZP, Yue TX (2012) Development of a surface modeling method for mapping soil properties. J Geogr Sci 22:752-760

Somasundaram D (2005) Differential geometry. Alpha Science International Ltd, Harrow

Tong ST, Naramngam S (2007) Modeling the impacts of farming practices on water quality in the little Miami river basin. Environ Manage 39:853-866

Vieux BE (2001) Distributed hydrologic modeling using GIS. Water Science and Technology Library, Kluwer Academic Publishers

Wang SW, Li WJ (2007) Climate of China. China Meteorological Press, Beijing

Wang CH, Zhang JS, Yan XD (2012) The use of geographically weighted regression for the relationship among extreme climate indices in China. Math Probl Eng. doi:10.1155/2012/369539

Xu CY, Singh VP (1998) A review on monthly water balance models for water resources investigations. Water Resour Manage $12: 31-50$

Yatagay A, Kamiguchi K, Arakawa O, Hamada A, Yasutomi N, Kitoh A (2012) APHRODITE constructing a longterm daily gridded precipitation dataset for Asia based on a dense network of rain gauges. Bull Am Meteorol Soc 93:1401-1415

Yue TX (2011) Surface modeling: high accuracy and high speed methods. CRC Press, New York

Yue TX, Wang Q, Lu YM, Xin XP, Zhang HB, Wu SX (2010a) Change trends of food provisions in China. Glob Planet Change $72: 118-130$

Yue TX, Song DJ, Du ZP, Wang W (2010b) High-accuracy surface modelling and its application to DEM generation. Int J Remote Sens 31:2205-2226

Yue TX, Fan ZM, Chen CF, Sun XF, Li BL (2011) Surface modeling of global terrestrial ecosystems under three climate change scenarios. Ecol Model 222:2342-2361

Yue TX, Zhao N, Ramsey RD, Wang CL, Fan ZM, Chen CF, Lu YM, Li BL (2013) Climate change trend in China, with improved accuracy. Clim Change 120:137-151

Zhao N, Yue TX (2014) A modification of HASM for interpolating precipitation in China. Theor Appl Climatol 116:273-285 